\title{
Tooth Brushing, Flossing, and Preventive Dental Visits by Detroit-area Residents in Relation to Demographic and Socioeconomic Factors
}

\author{
David L. Ronis, PhD \\ Institute for Social Research \\ University of Michigan, and \\ Department of Veterans Affairs
}

\author{
W. Paul Lang, DDS, MPH \\ Mahassen M. Farghaly, BDS, PhD
}

School of Dentistry

\section{Elaine Passow, MSW}

Institute for Social Research

University of Michigan

Ann Arbor, $\mathrm{Ml}$

\begin{abstract}
A survey was conducted to identify (a) factors that influence preventive dental behaviors and (b) target groups for interventions. Data were collected in face-toface interviews with a probability sample of 662 dentate adults living in the Detroit tricounty area. The interviews included questions about demographic and socioeconomic variables and about three preventive behaviors: brushing, flossing, and preventive dental visits. All behaviors were positively associated with socioeconomic status. Females were more likely than males to performeach of the behaviors at the recommended frequency. The behaviors were only weakly associated with age. Whites were more likely than nonwhites to make regular dental visits, but frequency of brushing and flossing did not vary substantially across racial groups. The impact of race on frequency of dental visits was reduced when socioeconomic status was statistically controlled. Findings suggest that socioeconomic status, race, and sex remain important considerations when planning dental health education or other interventions.
\end{abstract}

Key Words: preventive behavior, health services accessibility, dental self-care, dental care utilization.

Tooth decay, periodontal diseases, and tooth loss are significant problems in the United States, affecting mil-

Send correspondence and reprint requests to Dr. Ronis, 2254-ISR, University of Michigan, PO Box 1248, Ann Arbor, Ml 48106-1248. Manuscript received: $3 / 9 / 92$; returned to authors for revision: $5 / 8 / 92$; accepted for publication: 10/14/92. lions of Americans. Recent epidemiologic surveys suggest that more than a third of dentate adults have one or more unfilled carious lesions (1), about 44 percent of employed adults have some gingivitis (2), about 13 percent of employed adults have loss of periodontal attachment of at least $5 \mathrm{~mm}$ at one or more site (2), only about 15 percent of adults are free of any sign of periodontal diseases (3), and about 9 percent of all Americans are edentulous (4). Many of these problems are more common in older groups. For example, about 35 percent of employed adults 55-64 years of age have loss of periodontal attachment of at least $5 \mathrm{~mm}(2)$ and over onethird of adults 65 and older are edentulous $(4,5)$. These dental problems produce substantial burdens in discomfort and treatment cost.

To prevent dental problems or to provide early treatment, the American Dental Association and other organizations recommend that adults brush and floss their teeth at least once a day and obtain regular dental checkups $(6,7)$. Though research has not definitively established the utility of these actions or their most appropriate frequencies, the current study operates on the assumption that these recommended behaviors are useful. While over 90 percent of Americans brush daily (8), only about half have annual checkups and a minority floss daily $(9,10)$. The purpose of the current study was to determine how these behaviors are related to socioeconomic and demographic variables, in order to advance our understanding of why people do and do not follow these recommendations and to identify target groups that can most benefit from interventions to increase adherence to these recommended preventive dental behaviors.

Past surveys of preventive dental behaviors have 
found reliable differences across demographic subgroups and meaningful relationships with economic variables. Generally, women have been found to take preventive dental actions more often then men (8-12). These behaviors have been found to be positively associated with socioeconomic status (8,13-15). Use of professional dental services has been found to be negatively related to price $(1,13)$.

Though only a few studies have examined these behaviors across racial and ethnic groups, important differences have been found. Several studies have found that minority group members made fewer dental visits than non-Hispanic whites $(10,16-18)$. In contrast, in a study of low-income residents of Washington State, Kiyak (19) found that Asians were more likely than Caucasians to brush and floss at recommended frequencies. Past research has found inconsistent and usually weak relations between age and preventive dental behaviors $(8,11,12$, 15).

Many of the studies reviewed above are limited by examination of only one of the three behaviors (usually dental visits) and failure to distinguish preventive from restorative care. Other limitations of some of the past studies are use of nonprobability samples and failure to conduct multivariate analyses.

Some of these studies are significantly dated. A series of studies conducted for the American Dental Association has documented increases in dental preventive behaviors over time $(9,20,21)$. In light of historical changes and limitations of past studies, we sought to reexamine the relations between three dental preventive behaviors (brushing, flossing, and obtaining checkups) and socioeconomic and demographic variables in a probability sample of residents of a defined geographical area. Multivariate analyses were conducted to determine which of these variables are associated with dental preventive behaviors when other variables are controlled.

Based on past findings, we hypothesized that preventive dental behaviors would be more frequent among women and would be positively associated with socioeconomic status. Because of the greater expense of dental checkups compared to brushing and flossing, we predicted that checkups would be more strongly related (than brushing and flossing) to the economic predictor variables: income and dental insurance coverage. In light of some past findings and because minority status is typically associated with low socioeconomic status, we hypothesized that nonwhites would be less likely to perform the three preventive behaviors, but that the differences would be reduced or eliminated when socioeconomic status was controlled.

\section{Methods}

The study was a probability sample survey of adults 18 years of age or older having at least one tooth and living in housing units in the Detroit tricounty area. Data were collected in face-to-face interviews. Only one (randomly selected) eligible adult was interviewed in each selected housing unit. As a result, the probability of selecting a given individual was inversely proportional to the number of eligible persons in the household. Interviewing was conducted from August to November of 1989. The response rate was 72 percent and 622 interviews were obtained. The high response rate encourages us to believe that the respondents were representative of the defined population. All data were analyzed both with and without weighting by number of eligible respondents in the housing unit. Since weighting had very little effect (particularly on the bivariate and multivariate results), only the unweighted results are presented for most analyses. All relationships with the three behaviors were assessed by logistic regression analysis. Relations among predictors were tested by the chi-square test of association. For all analyses, alpha was set at .05 . There was some collinearity between education and income; however, results of the logistic regressions indicated it did not present enough of a problem to necessitate deletion of one of these variables from all multivariate analyses.

Variables and Measures. The survey questionnaire was developed by the authors and staff of the Survey Research Center of the University of Michigan Institute for Social Research. It was refined based on comments from consultants and feedback from three rounds of pilot testing by experienced interviewers. Brushing and flossing frequency were each assessed by a single question: "In general, how often did you (brush) (floss) your teeth during the past year?" For the current analyses, the answers were coded 1 if the person took the action at least once a day and 0 if less than once a day.

The term "checkup" was used in the interview to refer to a preventive dental visit. Checkups were defined for the subjects as "...visits to a dental office or clinic made not because of any dental problem." Two questions were asked to determine whether subjects made preventive visits at least once a year. The first question asked whether the subject had ever had a checkup. The second question (asked only of those who indicated ever having had a checkup) asked, "During the past five years, how often have you gone to a dentist or dental clinic for a checkup?" For the current analyses, the answers were coded 1 if the subject had checkups at least once a year and 0 if less than once a year (including never).

Reported year of birth was recoded to age at end of 1989 in four categories: $18-29,30-39,40-54$, and 55 and older. Race/ethnicity (hereafter called race) was determined by the interviewer's observation, originally recorded in the categories white, black, Asian/Pacific Islander, Hispanic, American Indian, and other. There were only 10 respondents in categories other than black and white. Preliminary analyses showed similar results for blacks and other minorities. So, for further analyses, all the minority categories were combined into a single 
"nonwhite" category. Sex was also determined by interviewer observation.

Socioeconomic status (SES) was represented by two separate variables, education and income, each assessed by a single question. The education question was, "What is the highest grade of school or year of college you completed?" For analysis, answers were recoded into the following categories: less than high school graduate, high school graduate-no college, one to two years of college, and three or more years of college. Subjects were asked to report their total family income for the year 1988 before taxes. Answers were recoded into four categories: less than $\$ 20,000, \$ 20,000-\$ 34,999, \$ 35,000-\$ 50,999$, and $\$ 51,000$ or higher.

Finally, a question asked whether subjects had any dental insurance. This variable was coded 1 if the subject reported any dental insurance (including Medicaid) and 0 if the subject reported no dental insurance.

\section{Results}

Weighted and unweighted distributions for all variables are shown in Table 1. Consistent with past findings, a high proportion of persons reported brushing at least once a day, a minority reported daily flossing, and an intermediate proportion indicated obtaining annual checkups. The weighted and unweighted results were very similar. The biggest difference between them was in income, reflecting the fact that a household with more than one adult is likely to have a higher total income. (Individuals from households with more than one eligible respondent were weighted up to compensate for their lower probability of selection.)

Table 1 also presents 1990 census data for the Detroit tricounty area to help assess the representativeness of the sample. Though our data and the census data have similar age and sex distributions, they are notably discrepant on race. This is partially due to a difference between the response rates in high-black-density neighborhoods $(63.2 \%)$ and other neighborhoods (73.9\%). This differential response rate slightly reduces the representativeness of the sample and can account for about one-third of the discrepancy between the race distributions of the sample and the census. Most of the discrepancy is apparently due to differences between the population we attempted to sample and the full area population. Our study was restricted to dentate adults living in housing units, while the census attempted to count all residents, including persons who are under 18 years of age, edentulous, and / or residing in prisons, rooming houses, and other places housing unrelated groups of persons-persons who were not eligible for inclusion in this study. These ineligible groups include relatively high proportions of minorities.

Tables 2 through 4 describe the bivariate and multivariate relationships between each of the three behaviors and the predictor variables. Results for brushing, floss-
TABLE 1

Distribution of All Measures

\begin{tabular}{|c|c|c|c|c|}
\hline & \multicolumn{3}{|c|}{ Nonmissing } & \multirow[b]{2}{*}{$\begin{array}{c}\text { \% of Pop. } \\
\text { (1990 } \\
\text { Census) }\end{array}$} \\
\hline & $\begin{array}{l}\text { No. of } \\
\text { Cases } \\
\end{array}$ & $\begin{array}{c}\text { Unweight- } \\
\text { ed } \\
\%\end{array}$ & $\begin{array}{c}\text { Weight- } \\
\text { ed } \%\end{array}$ & \\
\hline Brushing & 662 & & & \\
\hline Daily & & 96.4 & 96.3 & \\
\hline$<$ daily & & 3.6 & 3.7 & \\
\hline Flossing & 662 & & & \\
\hline Daily & & 31.6 & 30.1 & \\
\hline$<$ daily & & 68.4 & 69.9 & \\
\hline Checkups & 661 & & & \\
\hline Annually & & 72.9 & 74.5 & \\
\hline$<$ annually & & 27.1 & 25.5 & \\
\hline Age & 660 & & & \\
\hline$<30$ & & 24.1 & 27.1 & $25.0^{*}$ \\
\hline $30-39$ & & 28.0 & 27.3 & 23.1 \\
\hline $40-54$ & & 23.2 & 23.6 & 23.7 \\
\hline $55+$ & & 24.7 & 22.0 & 28.1 \\
\hline Race & 658 & & & \\
\hline White & & 82.2 & 84.7 & 72.4 \\
\hline Nonwhite & & 17.8 & 15.3 & 27.6 \\
\hline Sex & 662 & & & \\
\hline Male & & 41.1 & 43.1 & 48.0 \\
\hline Female & & 58.9 & 56.9 & 52.0 \\
\hline Education & 661 & & & \\
\hline$<12$ years & & 14.2 & 12.3 & \\
\hline 12 years & & 32.4 & 32.1 & \\
\hline $13-14$ years & & 24.7 & 26.4 & \\
\hline $15+$ years & & 28.7 & 29.3 & \\
\hline Income & 612 & & & \\
\hline$<\$ 20,000$ & & 21.7 & 16.9 & \\
\hline$\$ 20,000-34,999$ & & 24.0 & 22.1 & \\
\hline$\$ 35,000-50,999$ & & 25.7 & 27.2 & \\
\hline$\$ 51,000+$ & & 28.6 & 33.8 & \\
\hline Insurance & 655 & & & \\
\hline None & & 32.4 & 31.7 & \\
\hline Some & & 67.6 & 68.3 & \\
\hline
\end{tabular}

*Among persons 18 and older.

ing, and preventive visits are shown in Tables 2, 3, and 4, respectively. The left sides of these tables describe the bivariate relationships between behavior and each predictor by showing the percentage of persons in each group performing the behavior at the recommended frequency, the $P$-value derived from the Wald test in bivariate logistic regression, and odds ratios derived from that analysis. The odds ratio of 1 is indicated for the reference category with which the other categories were compared. The right side of these tables describes the multivariate relationship of the behavior to the predictors by present- 
TABLE 2

Relations Between Brushing and Predictor Variables $(N=599)$

\begin{tabular}{|c|c|c|c|c|c|}
\hline & \multicolumn{3}{|c|}{ Bivariate Statistics } & \multicolumn{2}{|c|}{ Multivariate Statistics } \\
\hline & \% Brushing & $P$ & Odds Ratio & $P$ & Odds Ratio (95\% CI) \\
\hline Age (years) & & $.859 \mathrm{NS}$ & & $.484 \mathrm{NS}$ & \\
\hline$<30$ & 95.3 & & 0.61 & & $0.86(0.23-3.21)$ \\
\hline $30-39$ & 97.1 & & 1 & & 1 \\
\hline $40-54$ & 95.7 & & 0.68 & & $0.50(0.13-1.92)$ \\
\hline $55+$ & 95.7 & & 0.66 & & $1.46(0.37-5.83)$ \\
\hline Race & & $.979 \mathrm{NS}$ & & $.192 \mathrm{NS}$ & \\
\hline White & 96.0 & & 1 & & 1 \\
\hline Nonwhite & 96.0 & & 1.01 & & $2.39(0.65-8.88)$ \\
\hline Sex & & $<.001$ & & $<.001$ & \\
\hline Male & 91.7 & & 1 & & 1 \\
\hline Female & 99.1 & & 10.42 & & $17.47(4.83-63.20)$ \\
\hline Education (years) & & .001 & & .022 & \\
\hline$<12$ & 87.1 & & 0.26 & & $0.33(0.10-1.02)$ \\
\hline 12 & 96.3 & & 1 & & 1 \\
\hline $13-14$ & 96.7 & & 1.14 & & $1.28(0.37-4.42)$ \\
\hline $15+$ & 99.4 & & 6.66 & & $7.06(0.81-61.26)$ \\
\hline Income & & .007 & & .028 & \\
\hline$<\$ 20,000$ & 90.6 & & 0.48 & & $0.41(0.13-1.25)$ \\
\hline$\$ 20,000-34,999$ & 95.2 & & 1 & & 1 \\
\hline$\$ 35,000-50,999$ & 98.0 & & 2.48 & & $3.22(0.72-14.41)$ \\
\hline$\$ 51,000+$ & 98.8 & & 4.25 & & $3.42(0.62-19.03)$ \\
\hline Insurance & & $.264 \mathrm{NS}$ & & $.857 \mathrm{NS}$ & \\
\hline None & 94.7 & & 1 & & 1 \\
\hline Some & 96.6 & & 1.61 & & $1.09(0.42-2.83)$ \\
\hline
\end{tabular}

NS=not significant.

ing $P$-values from $W$ ald tests in multiple logistic regression predicting the behavior from all six predictors, the odds ratios from this analysis, and confidence intervals for these odds ratios. This part of the tables characterizes the relationships when all of the other predictors are controlled. Further multivariate analyses, not shown in the tables, were conducted to clarify results of the bivariate and full multivariate analyses.

Brushing. As may be seen in Table 2, daily brushing had statistically significant relationships with sex and with the two variables indicating socioeconomic status: education and income, but not with age, race, or dental insurance coverage. The bivariate and multivariate analyses showed the same relationships. The strongest effect was that for sex, with an odds ratio greater than 10 , statistically significant at the .001 level in both analyses. Women were more likely than men to brush their teeth at least once a day. The percentage of persons brushing daily increased steadily with increases in education and income.

Flossing. As shown in Table 3, daily flossing had statistically significant bivariate relationships with sex, ed- ucation, and age, but not with income, race, or insurance. Women and older persons were more likely to floss and persons with low education were less likely to floss. Each of these relationships was also apparent in the odds ratios from the multivariate analysis.

One relationship that had not been significant in the bivariate analysis was statistically significant in the multivariate analysis. Controlling for other predictors, nonwhites were more likely than whites to report flossing. This finding is sufficiently incongruous with past results to raise the possibility that it is due to differences in reporting rather than to differences in flossing behavior. The fact that it appeared only in the multivariate analysis additionally suggests that other factors associated with race were reducing the performance or report of flossing behavior.

Preventive Dental Visits. As shown in Table 4, the behavior of making preventive dental visits at least once a year was significantly associated with each of the six predictor variables. As was the case for brushing and flossing, females were more likely than males to obtain dental checkups. Having preventive dental visits was 
TABLE 3

Relations Between Flossing and Predictor Variables $(N=599)$

\begin{tabular}{|c|c|c|c|c|c|}
\hline & \multicolumn{3}{|c|}{ Bivariate Statistics } & \multicolumn{2}{|c|}{ Multivariate Statistics } \\
\hline & $\%$ Flossing & $P$ & Odds Ratio & $P$ & Odds Ratio (95\% CI) \\
\hline Age (years) & & .027 & & $<.001$ & \\
\hline$<30$ & 24.8 & & 0.74 & & $0.82(0.49-1.36)$ \\
\hline $30-39$ & 31.0 & & 1 & & 1 \\
\hline $40-54$ & 34.8 & & 1.19 & & $1.31(0.80-2.15)$ \\
\hline $55+$ & 41.3 & & 1.57 & & $2.47(1.48-4.13)$ \\
\hline Race & & $.493 \mathrm{NS}$ & & .035 & \\
\hline White & 32.1 & & 1 & & 1 \\
\hline Nonwhite & 35.6 & & 1.17 & & $1.78(1.04-3.04)$ \\
\hline Sex & & .011 & & .003 & \\
\hline Male & 27.0 & & 1 & & 1 \\
\hline Female & 36.9 & & 1.58 & & $1.77(1.22-2.57)$ \\
\hline Education (years) & & .006 & & .003 & \\
\hline$<12$ & 16.5 & & 0.41 & & $0.40(0.20-0.79)$ \\
\hline 12 & 32.4 & & 1 & & 1 \\
\hline $13-14$ & 38.8 & & 1.32 & & $1.51(0.94-2.42)$ \\
\hline $15+$ & 35.6 & & 1.15 & & $1.31(0.82-2.09)$ \\
\hline Income & & $.068 \mathrm{NS}$ & & $.076 \mathrm{NS}$ & \\
\hline$<\$ 20,000$ & 23.4 & & 0.59 & & $0.53(0.29-0.97)$ \\
\hline$\$ 20,000-34,999$ & 34.0 & & 1 & & 1 \\
\hline$\$ 35,000-50,999$ & 38.2 & & 1.20 & & $1.18(0.71-1.95)$ \\
\hline$\$ 51,000+$ & 33.7 & & 0.99 & & $0.87(0.52-1.46)$ \\
\hline Insurance & & $.245 \mathrm{NS}$ & & $.506 \mathrm{NS}$ & \\
\hline None & 29.4 & & 1 & & 1 \\
\hline Some & 34.2 & & 1.25 & & $1.15(0.76-1.73)$ \\
\hline
\end{tabular}

NS=not significant.

strongly associated with socioeconomic status as indicated by highly significant relationships with education and income. The percentage of persons obtaining checkups increased with increasing levels of education and income up to the highest two levels. As anticipated, having dental insurance greatly increased the chance that an individual would obtain dental checkups. This contrasted with the other two behaviors, which were not significantly associated with insurance coverage.

Nonwhites were less likely than whites to make preventive dental visits. This finding was stronger in the bivariate analysis than in the multivariate analysis, suggesting that part of the effect of race on checkups might be explained or mediated by the other variables that were associated with both race and with the behavior. Examination of the bivariate relationships indicated that race was strongly associated with education $\left(\chi^{2}(3)=18.4\right.$, $P=.0004)$ and income $\left(\chi^{2}(3)=92.3, P<.0001\right)$ in ways that might explain the relationship between race and preventive visits. That is, nonwhites tended to have low levels of education and income. Race was associated with sex $\left(\chi^{2}(1)=9.26, P=.0024\right)$ and with insurance $\left(\chi^{2}(1)=10.9\right.$,
$P=.0010$ ) in ways that could not explain the relationship between race and preventive visits; a higher proportion of nonwhites than whites were female and reported having dental insurance. (The surprising finding that nonwhites were more likely than whites to report having dental insurance was observed for respondents at all levels of income, so it is not due to dental insurance provided by Medicaid.) Results of a multiple logistic regression predicting preventive visits from race, education, and income were consistent with the idea of mediation of the race effect by these factors. The effect of race on checkups was much weaker and nonsignificant in this analysis (Wald's $\chi^{2}(1)=2.15, P=.142$ ), indicating that the race effect could be largely explained by socioeconomic status.

The percentage of persons making annual preventive visits was a curvilinear function of age, with subjects 30 to 54 years old more likely than either older or younger subjects to have annual checkups. The relationship between age and preventive visits was statistically significant in the bivariate analysis, but not in the multivariate analysis, suggesting that some of the other predictors 
TABLE 4

Relations Between Preventive Visits and Predictor Variables $(N=598)$

\begin{tabular}{|c|c|c|c|c|c|}
\hline & \multicolumn{3}{|c|}{ Bivariate Statistics } & \multicolumn{2}{|c|}{ Multivariate Statistics } \\
\hline & $\%$ w/ Annual Checkups & $P$ & Odds Ratio & $P$ & Odds Ratio $(95 \% \mathrm{CI})$ \\
\hline Age (years) & & .021 & & $.117 \mathrm{NS}$ & \\
\hline$<30$ & 66.4 & & 0.57 & & $0.67(0.39-1.16)$ \\
\hline $30-39$ & 77.8 & & 1 & & 1 \\
\hline $40-54$ & 80.9 & & 1.21 & & $1.26(0.69-2.32)$ \\
\hline $55+$ & 70.8 & & 0.69 & & $1.22(0.68-2.22)$ \\
\hline Race & & $<.001$ & & .014 & \\
\hline White & 77.3 & & 1 & & 1 \\
\hline Nonwhite & 58.4 & & 0.41 & & $0.49(0.28-0.86)$ \\
\hline Sex & & .003 & & $<.001$ & \\
\hline Male & 67.7 & & 1 & & 1 \\
\hline Female & 78.7 & & 1.76 & & $2.56(1.67-3.93)$ \\
\hline Education (years) & & $<.001$ & & $<.001$ & \\
\hline$<12$ & 50.6 & & 0.45 & & $0.68(0.37-1.24)$ \\
\hline 12 & 69.5 & & 1 & & 1 \\
\hline $13-14$ & 82.9 & & 2.12 & & $2.41(1.36-4.28)$ \\
\hline $15+$ & 82.8 & & 2.10 & & $2.28(1.30-4.00)$ \\
\hline Income & & $<.001$ & & .017 & \\
\hline$<\$ 20,000$ & 50.8 & & 0.39 & & $0.53(0.30-0.95)$ \\
\hline$\$ 20,000-34,999$ & 72.8 & & 1 & & 1 \\
\hline$\$ 35,000-50,999$ & 83.6 & & 1.90 & & $1.46(0.80-2.68)$ \\
\hline$\$ 51,000+$ & 84.2 & & 1.99 & & $1.31(0.71-2.43)$ \\
\hline Insurance & & $<.001$ & & $<.001$ & \\
\hline None & 59.9 & & 1 & & 1 \\
\hline Some & 80.5 & & 2.77 & & $2.87(1.84-4.47)$ \\
\hline
\end{tabular}

NS=not significant.

could explain the effect of age on checkups. Bivariate analyses indicated age was significantly associated with insurance $\left(\chi^{2}(3)=21.2, P=.0001\right)$, education $\left(\chi^{2}(9)=28.2\right.$, $P=.0009)$, and income $\left(\chi^{2}(9)=42.5, P=.0001\right)$. In each case the form of the relationship was similar to that of the relationship between age and preventive visits. Specifically, the two middle age groups were more likely than the others to have dental insurance, the oldest group was the least likely to have attended college, and the two middle age groups were more likely than the others to have high levels of income. In a multiple logistic regression predicting checkups from age, insurance, education, and income, age was not a significant predictor of checkups (Wald's $\chi^{2}(3)=5.85, P=.1193$ ). This finding further supported the possibility that the effect of age on checkups could be explained and better understood by considering these other variables.

\section{Discussion}

This paper focuses on describing and understanding differences among demographic subgroups in their use of preventive dental behaviors. The results can be used to select target groups for interventions. Before addressing differences among groups, we would like to describe current dental health education interventions in this area and to point out differences among the behaviors. The main sources of dental health education in the Detroit tricounty area are commercial messages promoting dental care products and oral hygiene education provided in dental offices and clinics. School health education programs also include some coverage of dental health. There are no large-scale community dental health education programs in the area. New interventions are likely to be most successful if they take past programs into account.

Differences in performance of the three behaviors are also important for planning new interventions. While more than nine out of 10 subjects reported daily brushing, fewer than three out of four reported annual preventive visits and fewer than one out of three reported daily flossing. These differences are greater than the differences between demographic subgroups, suggesting that targeting interventions to specific behaviors may be more important than targeting interventions to groups of people. The findings suggest that there is little need to in- 
crease the frequency of brushing, but more substantial need for interventions to increase frequency of flossing and preventive visits. Detailed analysis of these differences among behaviors is presented elsewhere (22). The impact of interventions can be maximized if they are targeted to specific behaviors and to specific groups of persons.

The first hypothesis of the study was that preventive dental behaviors would be more commonly practiced by women than by men. This hypothesis was supported. Women were significantly more likely than men to perform each of the behaviors (brushing, flossing, and making preventive visits) at the recommended frequencies. This is consistent with past results for these behaviors $(8,9,11,12)$ and with most research on sex differences in preventive health behaviors (23-26). Past discussions of similar findings have suggested that they result both from a greater interest in health among women and from greater social pressures on women to be physically attractive $(23,25-28)$. These differences apparently have persisted. In terms of practical application, these findings suggest that while women may be more receptive to health education communications and other interventions encouraging preventive dental behaviors, men are more in need of such interventions.

The second hypothesis was that all three behaviors would be positively associated with socioeconomic status, as they were in past studies $(1,8,13-15)$. As predicted, the likelihood of daily brushing, daily flossing, and regular preventive visits was higher among persons with higher levels of education and income (the two indicators of socioeconomic status). The relationships between education and the behaviors tended to be stronger than the relationships between income and the behaviors. Those findings, along with the fact that brushing and flossing are inexpensive, suggest that cultural differences (differing beliefs, attitudes, knowledge, and traditions) are more important than financial differences in explaining the impact of socioeconomic status on brushing and flossing. These results also suggest that groups with low income or education are important targets for action programs to increase dental preventive behaviors.

The third hypothesis was that, because of their cost, preventive dental visits would be more strongly associated with economic variables (income and insurance) than would the other two behaviors (29). Comparison of Tables 2 through 4 provides little support for this hypothesis as it applies to income. Odds ratios suggest that income was more important in predicting preventive visits than in predicting flossing, but that income was a stronger predictor of brushing than of visits. Comparisons of odds ratios provide overwhelming evidence for the stronger relationship between insurance and visits than between insurance and the other behaviors. In addition, insurance was not a significant predictor of brushing or flossing, but was statistically significant at beyond the .001 level in both bivariate and multivariate analyses of preventive dental visits.

The strong influence of insurance on utilization of dental services is consistent with past findings $(1,8,13-15)$ and with theory (29), and suggests that interventions to facilitate appropriate utilization of preventive services by low-income populations may have greatest success if they directly address the financial barriers by providing insurance, free care, or care at very reduced prices. In some countries other than the United States (e.g., the Netherlands, United Kingdom, Denmark, Sweden, Iceland, and France), dental care for most residents has been provided or subsidized by the government, reducing cost as a barrier to care and income differentials in utilization (30). (Admittedly, there are other barriers to care and the overall level of utilization in these countries is not outstandingly high.)

The fourth hypothesis was that nonwhites would be less likely than whites to brush, floss, and obtain dental checkups at the recommended frequencies, but that such differences would be reduced or eliminated when socioeconomic status was controlled. Consistent with this hypothesis, nonwhites were less likely than whites to obtain annual checkups and this difference was greatly reduced when socioeconomic status (represented by education and income) was statistically controlled. The effect of race on frequency of checkups was largely explained by socioeconomic status. Nonwhites, however, were not significantly less likely than whites to brush or floss daily.

In light of the limited information available from past research, no predictions were made about age in relation to these behaviors. Though age was not substantially related to brushing, older persons were more likely to report daily flossing. In the bivariate analysis, age had a significant nonmonotonic relationship with preventive visits; persons in the middle two age groups were more likely than those under 30 or those 55 and older to have annual checkups. Multivariate analyses suggested that this relationship might be explained by differences in insurance and socioeconomic status between the age groups. Additionally, it is plausible that (though dentate) the oldest group was likely to have fewer teeth, and for that reason to feel less need for dental services.

Though the effects of race and age may be explained or mediated by socioeconomic variables, race and age can be used to identify target groups for interventions. People tend to be more interested in messages that appear to be designed specifically for them than equally relevant messages aimed to a larger group (31). So blacks are more likely to pay attention to a televised dental health message showing black actors than to one that does not. In sum, there are substantial associations of preventive dental behaviors with demographic and socioeconomic variables. Regular brushing, flossing, and preventive dental visits were more common among women and persons of higher socioeconomic status. In addition, preventive 
dental visits were more likely to be made by whites, by persons 30-54 years of age, and by persons with dental insurance. These findings can be used to identify target groups for intervention. The results suggest that interventions to increase the regularity of preventive dental visits among the poor will be most successful if they directly address economic barriers.

\section{Acknowledgments}

This study was supported by NIDR grant \#DE07800 to the first author. We thank Brian Burt for comments on the manuscript, Sarah Ekdahl for comments on the manuscript and assistance in data analysis, and the University of Michigan Center for Statistical Consultation and Research for advice on logistic regression.

\section{References}

1. Bonito AJ, Iannacchione $V$, Jones S, Stuart $C$. The impact of prepaid dental care on dental service utilization and oral health. Research Triangle Park, NC: Research Triangle Institute, 1986.

2. Brown LJ, Oliver RC, Löe H. Evaluating periodontal status of US employed adults. J Am Dent Assoc 1990;121:226-32.

3. Brown LJ, Oliver RC, LöeH. Periodontal diseases in the US in $198 \mathrm{I}$ : prevalence, severity, extent, and role in tooth mortality. J Periodontol 1989;60:363-70.

4. Ismail AI, Burt BA, Hendershot GE, Jacks S, Corbin SB. Findings from the dental care supplement of the National Health Interview Survey, 1983. J Am Dent Assoc 1987;114:617-21.

5. Miller AJ, Brunelle JA, Carlos JP, Brown LJ, Löe H. Oral health of United States adults. The national survey of oral health in US employed adults and seniors: 1985-1986. National findings. Bethesda, MD: National Institute of Dental Research, 1987; NIH pub no 87-2868.

6. American Dental Association. Wake up to prevention for the smile of a lifetime. J Am Dent Assoc 1988;116:3g, 6g-13g.

7. National Institutes of Health. Rx for sound teeth. Washington, DC: US Government Printing Office, 1991; NIH pub no 91-3245.

8. Swank ME, Vernon SW, Lairson DR. Patterns of preventive dental behaviors. Public Health Rep 1986;101:175-84.

9. Chen M, Rubinson L. Preventive dental behavior in families: a national survey. J Am Dent Assoc 1982;105:43-6.

10. Hayward RA, Meetz HK, Shipiro MF, Freeman HE. Utilization of dental services: 1986 patterns and trends. J Public Health Dent 1989;49:147-52.

11. Helöe LA, Aaro LE, Sogaard J. Dental practices in Norwegian adults. Community Dent Oral Epidemiol 1982;10:308-12.

12. Schuurs AH, Duivenvoorden HJ, Velzen SK, Verhage F. Differentiating regular from irregular dental attenders of either sex by linear discriminant analysis. Community Dent Oral Epidemiol 1983;
11:43-9.

13. Petersen PE, Pedersen KM. Socioeconomic demand model for dental visits. Community Dent Oral Epidemiol 1984;12:361-5.

14. Rayner JF. Socioeconomic status and factors influencing the dental health practices of mothers. Am J Public Health 1970;60:1250-8.

15. Chen $\mathrm{M}$, Stone $\mathrm{DB}$. Toothbrushing, flossing, and dental visits in relation to socioeconomic characteristics of white American families. Community Dent Oral Epidemiol 1983;11:325-32.

16. Garcia JA, Juarez RZ. Utilization of dental health services by Chicanos and Anglos. J Health Soc Behav 1978;19:428-36.

17. Douglas CW, Cole KO. Utilization of dental services in the United States. J Dent Educ 1979;43:223-38.

18. Jack SS, Bloom B. Use of dental services and dental health: United States, 1988. Hyattsville, MD: National Center for Health Statistics, 1988; DHHS pub no (PHS) 88-1593 (Vital and health statistics, series 10 , no 165).

19. Kiyak HA. Dental beliefs, behaviors and health status among Pacific Asians and Caucasians. Community Dent Oral Epidemiol $1981 ; 9: 10-14$.

20. American Dental Association. Survey of family toothbrushing practices. J Am Dent Assoc 1966;72:1489-91.

21. Craig TT, Montague JL. Family oral health survey. J Am Dent Assoc 1976;92:326-332.

22. Ronis DL, Lang WP, Farghaly MM, Ekdahl SM. Prevalence of preventive behaviors. Manuscript under review. Currently available from the first author.

23. Langlie JK. Social networks, health beliefs, and preventive health behavior. J Health Soc Behav 1977;18:244-60.

24. Oleckno WA, Blacconiere MJ. A multiple discriminant analysis of smoking status and health-related attitudes and behaviors. Am J Prev Med 1990;6:323-9.

25. Rakowski W, Assaf AR, Lefebvre RC, Lasater TM, Niknian M, Carleton RA. Information-seeking about health in a community sample of adults: correlates and associations with other health-related practices. Health Educ Q 1990;17:379-93.

26. Selby R, Weinstein HM, Bird TS. The health of university athletes: attitudes, behaviors, and stressors. J Am Coll Health 1990;39:11-18

27. Ussher IM. The psychology of the female body. London: Routledge 1989.

28. Albino JE, Tedesco LA. Women's health issues. In: Rickel AU, Gerrard M, Iscoe I, eds. Social and psychological problems of women: prevention and crisis intervention. Washington, DC: Hemisphere Publishing, 1984:157-72.

29. Anderson R, Newman, JF. Societal and individual determinants of medical care utilization in the United States. Milbank Mem Fund Q 1973;51:95-125.

30. Fédération Dentaire Internationale. Basic fact sheets. London: Fédération Dentaire Internationale, 1984.

31. Lynch PD, Ronis DL. Cancer information for blacks: a radio program evaluation. In: Mettlin C, Murphy GP, eds. Issues in cancer screening and communication. New York: Alan R. Liss, 1982:399 408. 